\title{
A REMARKABLE NEW SPECIES OF PROCERATIUM, WITH DIETARY AND OTHER NOTES ON THE GENUS (HYMENOPTERA: FORMICIDAE) ${ }^{1}$
}

\author{
By William L. Brown, JR. \\ Department of Entomology \\ Cornell University \\ Ithaca, New York 14853
}

\section{INTRODUCTION}

The primary purpose of this paper is to describe an extraordinary new insect from Madagascar. This ant has, in effect, two tail ends, one of which, the false end, is a logical extension of the tendency in certain Proceratium species (e.g., P. pergandei and P. micrommatum) for the second gastric segment to extend rearward, while the true gastric apex projects from its ventral aspect in an anterior direction. The adaptive reason for this down-and-forward orientation of the true abdominal apex is not entirely understood, though it is clear that the deployment of the sting is usually an important feature of prey-attack in ponerine ants.

\section{Proceratium diplopyx new species}

Figs. 1, 2.

Holotype worker: TL 6.0, HL (including clypeus) 1.44, HW 1.25, ML (beyond clypeus) 0.15 , scape L 1.12, eye diameter 0.12 , WL 1.77 , petiole $\mathrm{L}$ in side view 0.70 , gaster $\mathrm{L} 1.97$, hind tibia $\mathrm{L} 1.26$, hind femur L $1.53 \mathrm{~mm}$. CI 87, SI 90. (A single paratype worker hardly differs from the holotype by more than the usual errors of measurement, except that the head is slightly wider: HW $1.29 \mathrm{~mm}$, CI 90.)

Habitus well portrayed in figures 1 and 2 . Figure 2 shows the head tilted slightly back from the full-face view plane, so that the posterior cephalic margin appears straight and is slightly surpassed by the scapes laid back in repose. In perfect full-face view, the center of the posterior margin is feebly concave, and the scape laid back does not

\footnotetext{
${ }^{1}$ A report of research from the Cornell University Agricultural Experiment Station, New York State College of Agriculture and Life Sciences. The research was supported in part by National Science Foundation Grant GB-31662
}

Manuscript received by the editor February 14, 1980 


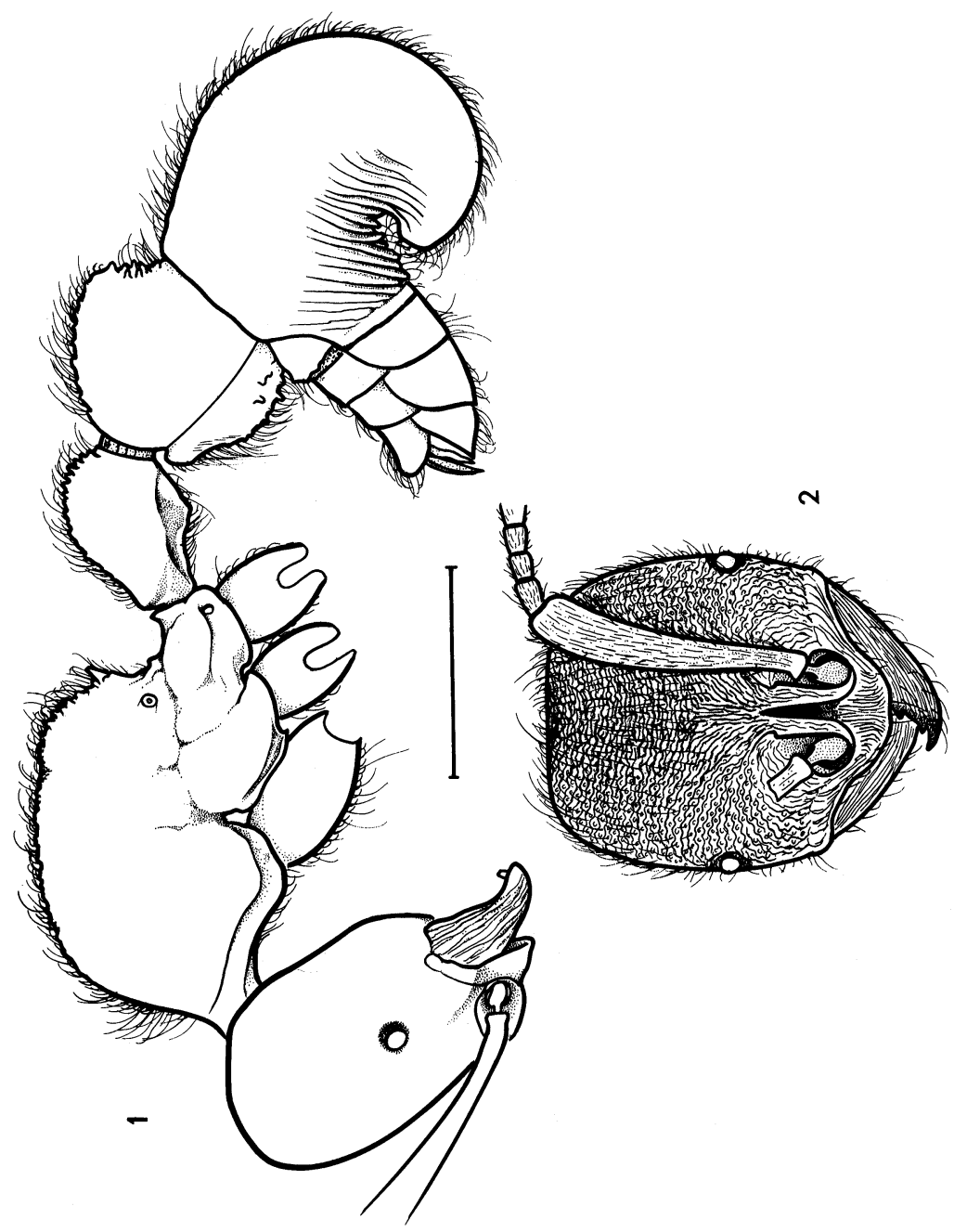

苍

की

.

害要

盾

중욜

는

요

츨

施

政

충

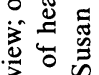

$>$ in

莺这

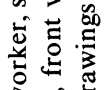

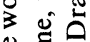

造

की

잉

is

远

के

है है

또

s.

원

ธ

돌

5

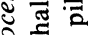

₹

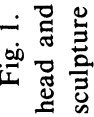


quite attain it. Median clypeal lobe raised, broad and rounded, with a faint median sulcus and a tendency toward flattening, or even shallow emargination, of the middle of its anterior border, especially as viewed when the head is tilted back. Frontal area narrow-lanceolate and deeply impressed. Eyes each composed of a single, large, clear, convex facet that projects beyond the lateral margins of the head in full-face view.

Mandibles each with 4 sharp teeth, including the apical; because of full closure, the presence of an additional tooth at the basal angle cannot definitely be excluded as a possibility. Labrum retracted against the rest of the under-mouthparts, difficult to see, but appears to be medially sulcate on its visible (extensor) surface and weakly bilobate, with a median excision of its free apical margin. Outside the lateral labral margins can be seen clearly 3 segments of each maxillary palp and 2 segments of each labial palp, so that the palpi must include at least 4 and 3 segments respectively.

Underside of head shallowly concave and weakly rugulose, sunken between thick, rough, raised, ventrolateral cephalic margins ("occipital carinae") that originate near the mandibular insertions.

Antennae with segment II (pedicel) longer than broad; III-VIII about as long as broad to slightly longer than broad; IX-XI slightly broader than long; apical segment about $2 \frac{1}{2}$ times as long as broad; the length-breadth ratios vary somewhat in different perpendicular views of the antennal axis.

Trunk as seen from dorsal view weakly pyriform, evenly convex and slightly broader across pronotum $(0.94 \mathrm{~mm}$ in holotype) than across propodeum and metathorax $(0.76 \mathrm{~mm})$, with only a very feeble constriction near truncal midlength, but convexities of mesonotum and propodeum as seen in side-view profile separated by a slight but distinct metanotal impression. Propodeum strongly convex in both directions, passing into declivity through a smooth curve flanked on each side by a short, upturned tooth; declivity smooth and shining, flanked on each side by a low margin bearing a short denticle at the bottom of each concavity, and an upturned, triangular, metapleural tooth or lobe at its ventral extremity.

Propodeal spiracle small, with a nearly round aperture, directed posterolaterad. A curved and rather deep sulcus marks the approximate juncture of propodeum with meso- and metathoracic sclerites below it. 
Petiolar node pyriform or subclavate, with feebly suggested peduncle, about $0.47 \mathrm{~mm}$ wide across the widest part (near posterior end) in holotype, and about $0.66 \mathrm{~mm}$ long. Ventral keel forming an obtuse tooth just behind midlength.

Postpetiole with broadly rounded sides, diverging caudad to the greatest width, a little before the posterior margin (W $0.89 \mathrm{~mm}$ in holotype), which is rather sharply constricted. Median posterodorsal surface of postpetiole weakly set off as a high, rounded boss; anteroventral shelf or lip well developed, trailing a short, septate carina caudad.

The remainder of the abdomen forms the most extraordinary structure of this body region known among the ants (figure 1). The second gastric (fourth true abdominal) tergum is grossly hypertrophied posteriad beyond the anteroventral opening, from which issues the true abdominal apex, with the exserted apical segments extending ventro-cephalad. The hypertrophied posterior extension of the second gastric tergum is permanently curled anteroventrad to form a short, bluntly rounded, false gastric apex, so that the real sternum of this segment is externally represented only by a small anteroventral piece, triangular in side view. The incurled ventral surface of the tergal extension is furnished with a series of coarse, sharp rugae that tend to extend vertically or obliquely part way up the lateral surfaces, and run partly transversely across the concavity in the holotype (in the paratype worker, the posterior rugae tend to run lengthwise, following the curve of the curl). From above, the hypertrophied tergum is cylindrical, $1.3 \mathrm{~mm}$ long, with almost straight (very feebly concave), parallel sides and a broadly rounded posterior outline, and is almost exactly $(0.87 \mathrm{~mm})$ as wide as the postpetiole. (In the paratype, maximum postpetiole $\mathrm{W} 0.92 \mathrm{~mm}$, maximum second tergal $\mathrm{W}$ $0.90 \mathrm{~mm}$.)

In both specimens the gastric apex is extended as 3 stout visible segments and the strong, exserted sting; undoubtedly these are all retractile to some degree.

Legs rather long and slender, though both femora and tibiae are gradually incrassated from base toward apex; hind leg: femur L 1.53, tibia L 1.26, metatarsus L $1.0 \mathrm{~mm}$. Tibial spurs one on each leg (small on mid tibia), pectinate, but only feebly so on mid tibia. Claws on all legs slender, simple. 
Head, trunk, petiole and postpetiole densely and moderately coarsely sculptured, opaque generally, but with minor glancing reflections here and there from individual rugulae or the bottoms of punctures. On the head, the sculpture is finest and most shallow, with rugulosity running in the directions shown in fig. 2, and more or less longitudinally on the sides of the head. Mandibles (except for their smooth, shining apices), median clypeus and frontal lobes rather coarsely and unevenly striate. Trunk, petiole and postpetiole densely rugose to scabriculous, becoming scabriculous-muriculate, or even denticulate on propodeum, petiolar node, and both tergum and sternum of postpetiole. Hidden throughout these roughly sculptured surfaces are numerous small but deep punctures with central, piligerous tubercles. The rugae of the postpetiole are longitudinal and subconcentrically curved as seen from above.

Second gastric (fourth true abdominal) tergum predominantly smooth and shining over most of its dorsal, lateral and posterior surfaces, but with numerous, spaced piligerous papillulae throughout, giving way to piligerous punctures caudad, and to the aforementioned rugae ventrad. Apical segments of gaster delicately strigulate, shining. Legs and antennae finely and densely reticulate-punctulate, the antennae distinctly so, and matt; the legs more superficially so, and weakly shining in part. Coxae obscurely rugulose in addition.

Body and appendages covered with an abundant pilosity consisting of fine, curved, tapered, whitish hairs, mostly 0.05 to $0.2 \mathrm{~mm}$ long and obliquely standing (straighter and more erect on clypeus, antennae and legs). A short, dense pubescence is also present and widespread, and especially noticeable on antennae and legs, where it is appressed or subappressed and lies longitudinally, and on posterior surface of large gastric tergite, where it is mostly decumbent. Apical gastric segments, especially the last two, with luxuriant bands or brushes of long, fine, pale hairs.

Body color deep reddish-brown, almost mahogany; second gastric (IV abdominal) segment brighter, more reddish; mandibles, antennae, legs and apical gastric segments ferruginous yellow.

Queen, male and larvae still unknown.

Holotype (Muséum National d'Histoire Naturelle, Paris) and one paratype worker (Museum of Comparative Zoology, Harvard University, Cambridge, Massachusetts, USA) taken in a leaf litter berlesate in "forêt dense humide de moyenne altitude" (about $1000 \mathrm{~m}$ ) at 
Iaraka, on the eastern side of the Baie d'Antongil, Province de Tamatave, Malagasy Republic, on 26 November 1969, by J. -M. Betsch.

This altogether extraordinary ant is distinguished at once from its congeners by the strongly produced and downcurved "false apex" of the second gastric segment, as well as by the form of the propodeum, and several minor characters of sculpture, etc. It is the first species of its genus to be taken on Madagascar, and its must be placed in a species group of its own. Its relatively large size, large but singlefacetted eyes, elongate petiole, coarse sculpture and developed propodeal teeth ally it with the stictum group of primitive species more closely than any other group.

\section{Proceratium micrommatum (Roger) $(=P$. convexiceps Borgmeier) new synonym}

Earlier (Brown 1974:82) I called attention to the doubtful status of P. convexiceps Borgmeier (1957:120-122, fig. 34). Not only do samples of this complex (including new collections from Honduras: Lancetilla, near Tela; and $14 \mathrm{~km} \mathrm{~S}$. La Ceiba; both in rotten logs, W. L. Brown, Jr.) vary in the development of the median clypeal process, which may be absent, weakly projecting, or strong, but it seems clear that the "Arbeiter" of micrommatum against which Borgmeier (1957:118-120) compared convexiceps was actually an ergatoid queen of micrommatum, so that differences in head shape, eye size and petiolar thickness are apparently only allometric caste differences.

A worker specimen of $P$. micrommatum from Honduras was dissected and proved to have maxillary palpi of 3 segments, the second segment having the "hammer-head" form characteristic of Proceratium, i.e., it is stalked from the side, and the apical segment has 3 long apical sensilla. Labial palpi with each 2 segments: basal segment narrower, apical segment claviform, with 3 long apical sensilla.

\section{Key to New World Proceratium, Workers}

1. Petiolar node in the form of a thick, erect scale with nearly parallel anterior and posterior faces (posterior face may be concave), apex truncate or subtruncate in side view; second gastric (IV true abdominal) segment curved downward, but neither 
strongly inflated nor produced caudad ............. 2 Petiolar node low and bun-shaped, or at least broad at base, with anterior and posterior faces strongly coverging to a rounded apex; second gastric segment strongly vaulted, inflated, and produced caudad behind the anteroventrally-protrusible true apical segments ......................... 3

2. Size larger, head width $>0.75 \mathrm{~mm}$ (SE U.S.) .... croceum Size smaller, head width $<0.75 \mathrm{~mm}$ (L. Ontario and Massachusetts s. to Florida and Honduras) ............ silaceum

3. Apical segments and sting issuing from near anteroventral end of second gastric segment, so that the sternum of this segment is very short - as seen from the side, not or scarcely more than half as long as sternum of preceding (postpetiolar) segment ...4 4 Apical gastric segments issuing from second gastric segment nearer to its posterior end, so that its sternum as seen from the side is subequal in length to that of the preceding segment (California) ........................... californicum

4. Larger species; head width without eyes $>0.80 \mathrm{~mm}$; anterior clypeal border produced as a median lobe that is emarginate apically $\ldots \ldots \ldots \ldots \ldots \ldots \ldots \ldots \ldots \ldots \ldots \ldots . \ldots \ldots$ Smaller species; head width without eyes $<0.80 \mathrm{~mm}$; anterior median lobe of clypeus absent or reduced to a small, rounded or single-pointed tooth $\ldots \ldots \ldots \ldots \ldots \ldots \ldots \ldots \ldots \ldots 6$

5. Very large species; head width $>1.0 \mathrm{~mm}$; petiole longer than deep, and slightly longer than broad in worker (Central America) ................................. goliath Medium-sized species; head width without eyes $<1.0 \mathrm{~mm}$; petiole about as high as long, and broader than long (forested E. USA north to Massachusetts) $\ldots . \ldots \ldots \ldots \ldots \ldots$........... pergandei

6. Trunk in side view with dorsal outline evenly convex from pronotum to top of propodeal declivity (Mexico to Ecuador, Cuba) ............................... micrommatum Trunk in side view with propodeal dorsum feebly concave in outline, then raised as a rounded angle or boss where it meets the declivity (SE Brasil) .................... brasiliense

\section{Proceratium numidicum in Europe}

Baroni Urbani (1977) calls into question my 1958 identification of Proceratium numidicum from Tirana, Albania, saying that "appar- 
ently this specimen has not been studied by Brown himself, but by Wilson ..." He adduces other circumstantial evidence to conclude that the Albanian specimen is really $P$. melinum. But Baroni Urbani never called for a loan of the specimen in question, which resides in the Museum of Comparative Zoology at Harvard University, and if he had done so, he would have been forced to conclude, as I was originally (Brown, 1958:334) after my own personal study of the same example, that the Tirana specimen is morphologically $P$. numidicum, and not $P$. melinum. The two species are in fact members of different species-groups. At my request, in 1955 or 1956, E. O. Wilson did compare the Albanian specimen with a type of $P$. numidicum (Brown, 1974: 82) in the Emery Collection. This comparison was based on my previous suspicion that the Albanian specimen (then under my care in MCZ) belonged to numidicum. Since that time, I have had ample opportunity to compare the relevant types directly with the Albanian specimen and to confirm once more my own opinion of its identity. Finzi's old determination as "europaea," as well as Baroni Urbani's conjecture, are both wrong. Unless the label data are in error, $P$. numidicum must be considered to occur in Balkan Europe.

\section{Egg Predation in Proceratium and some other ants}

The species of Proceratium are arthropod egg predators as far as is known. In Proceratium, $P$. silaceum has been observed feeding upon and storing eggs of spiders and (rarely) of another, unknown arthropod (Brown, 1958; the determination of P. silaceum was inadvertently omitted from the field and artificial nest observations). Since then, I have observed $P$. pergandei in Mississippi feeding on and storing spider eggs in a rotten-wood nest in nature; $P$. micrommatum from rotten-wood colonies from Lancetilla, near Tela, Honduras, feeding on spider eggs of two different kinds offered in the artificial nest; and $P$. avium carrying and storing eggs resembling spider eggs in Mauritius (Brown, 1974). Tests by me with all these species in the artificial nest failed to elicit any attempt by the ants to feed on sugary food, eggs of one or two kinds of millipedes, and various insect parts, but I did once get two $P$. silaceum workers to feed on a small droplet of yolk from a fresh hen's egg for periods of up to about 2 minutes at a time in the artificial nest. 
Observations of $P$. silaceum in artificial nests indicate that in this species the reflexed gastric tip is used to tuck the slippery eggs forward toward the mandibles when the eggs are being carried by the ants. Eggs of prey are stored in the ant nest in large numbers, recalling seed storage by the true harvester ants in subfamily Myrmicinae. Since Proceratium conceivably may belong to a group not too distant from the parent stock leading to the Myrmicinae, one may wonder whether the egg-collecting habit could have served as a key preadaptation to seed harvesting.

Ants of the related ectatommine genus Discothyrea also feed on arthropod eggs, probably usually those of spiders (though one small, undetermined Australian species has been found in nests of other ants). D. bidens (or near) is one egg-feeder in the wet mountain forests of New South Wales (Brown, 1958; embryos found in eggs packed in 4 nests of this ant appear to be those of spiders). In 1960, I found tiny spherical ova resembling spider eggs in a small nest cavity of a Discothyrea species (group of testacea) on Barro Colorado Island in the Panama Canal Zone. In 1969, in wet mountain forest in Hogsback Reserve, eastern Cape Province, South Africa, I found numerous spherical eggs resembling those of spiders, and also a few more elongate ova, in a nest of Discothyrea poweri in rotten wood.

Oligomyrmex species (subfamily Myrmicinae) may often be specialist egg predators, particularly of eggs of termites in rotten wood. A populous colony of $O$. urichi that I found in rotten wood in forest along the Rio Don Diego, Guajira Dept., Colombia, contained many spherical eggs of an unknown arthropod, ranging in color from nearly white to reddish-brown in color, as though in different stages of cuticular tanning. These eggs were fed upon by soldiers and workers of the ant, and slowly disappeared during several months of captivity in a plaster-bottomed nest in the laboratory.

W. H. Gotwald has given me specimens of a small new West African species of Plectroctena recently described as P. lygaria by Bolton, Gotwald and Leroux (1976), that was found to have stored large number of millipede eggs in its nest. The adult of at least some of the larger Plectroctena species are predators of adult millipedes.

The above sampling, by no means exhaustive, should demonstrate that arthropod egg predation is a significant adaptive zone exploited by a variety of ants. 


\section{References Cited}

Baroni URBANI, C.

1977. Les espèces européenes du genre Proceratium Roger (Hymenoptera: Formicidae). Mitt. Schweiz. Ent. Ges. 50: 91-93.

Bolton, B., W. H. Gotwald and J.-M. Leroux.

1976. A new West African ant of the genus Plectroctena with ecological notes (Hymenoptera: Formicidae). Ann. Univ. Abidjan (E) 9: 371-381.

BORGMEIER, T.

1957. Myrmecologische Studien. 1. An. Acad. Sci. Brasil. Ci. 29: 101-128. Brown, W. L., JR.

1958a. Contributions toward a reclassification of the Formicidae. II. Tribe Ectatommini (Hymenoptera). Bull. Mus. Comp. Zool. Harv. 118: 171-362.

1958b. Predation of arthropod eggs by the ant genera Proceratium and Discothyrea. Psyche 64: 115.

1974. A remarkable new island isolate in the ant genus Proceratium (Hymenoptera: Formicidae). Psyche 81: 70-83.

SNELling, R. R.

1967. Studies on California ants. 3. The taxonomic status of Proceratium californicum Cook (Hymenoptera: Formicidae). Contrib. Sci. Los Angeles Co. Mus. 124: 1-10. 

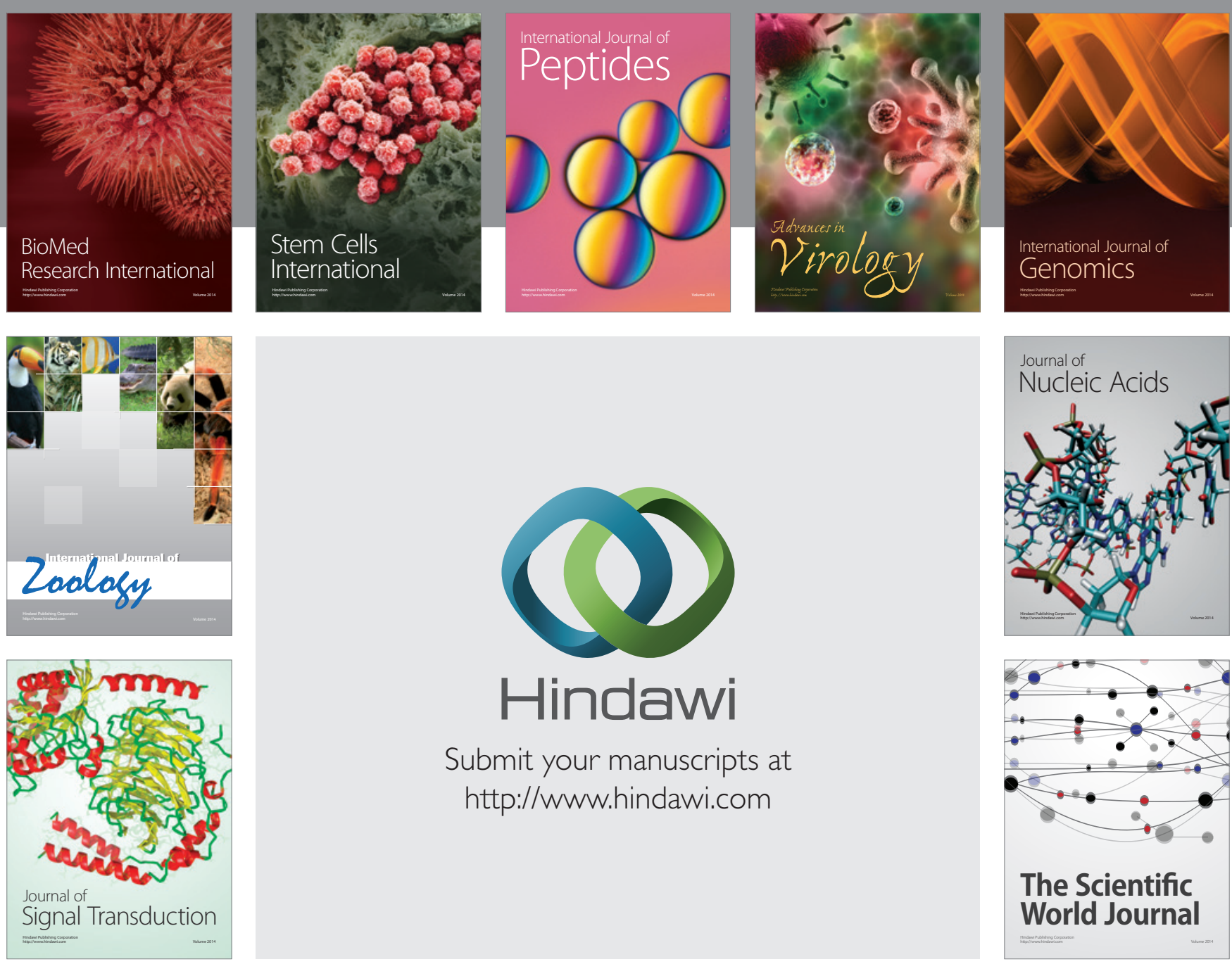

Submit your manuscripts at

http://www.hindawi.com
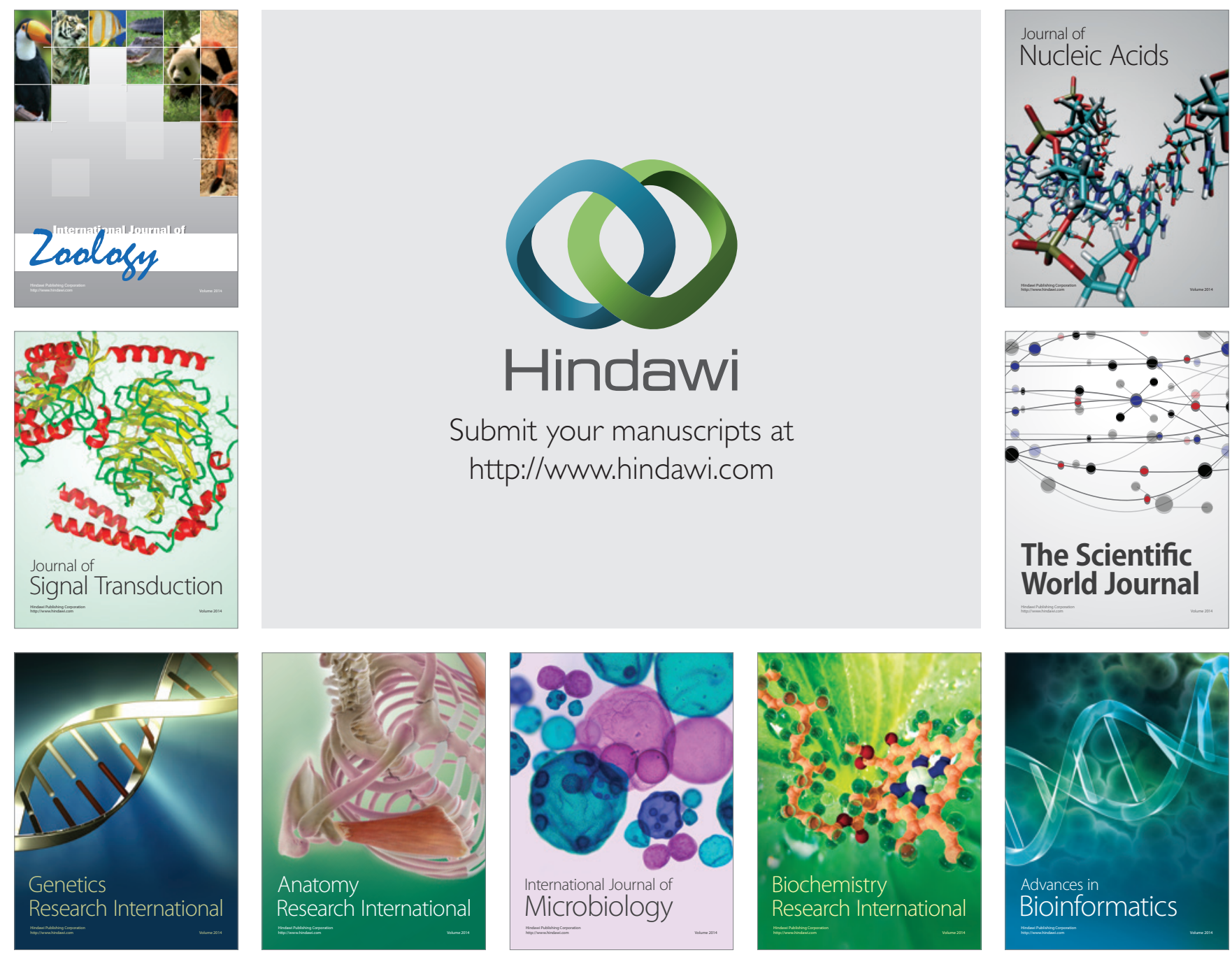

The Scientific World Journal
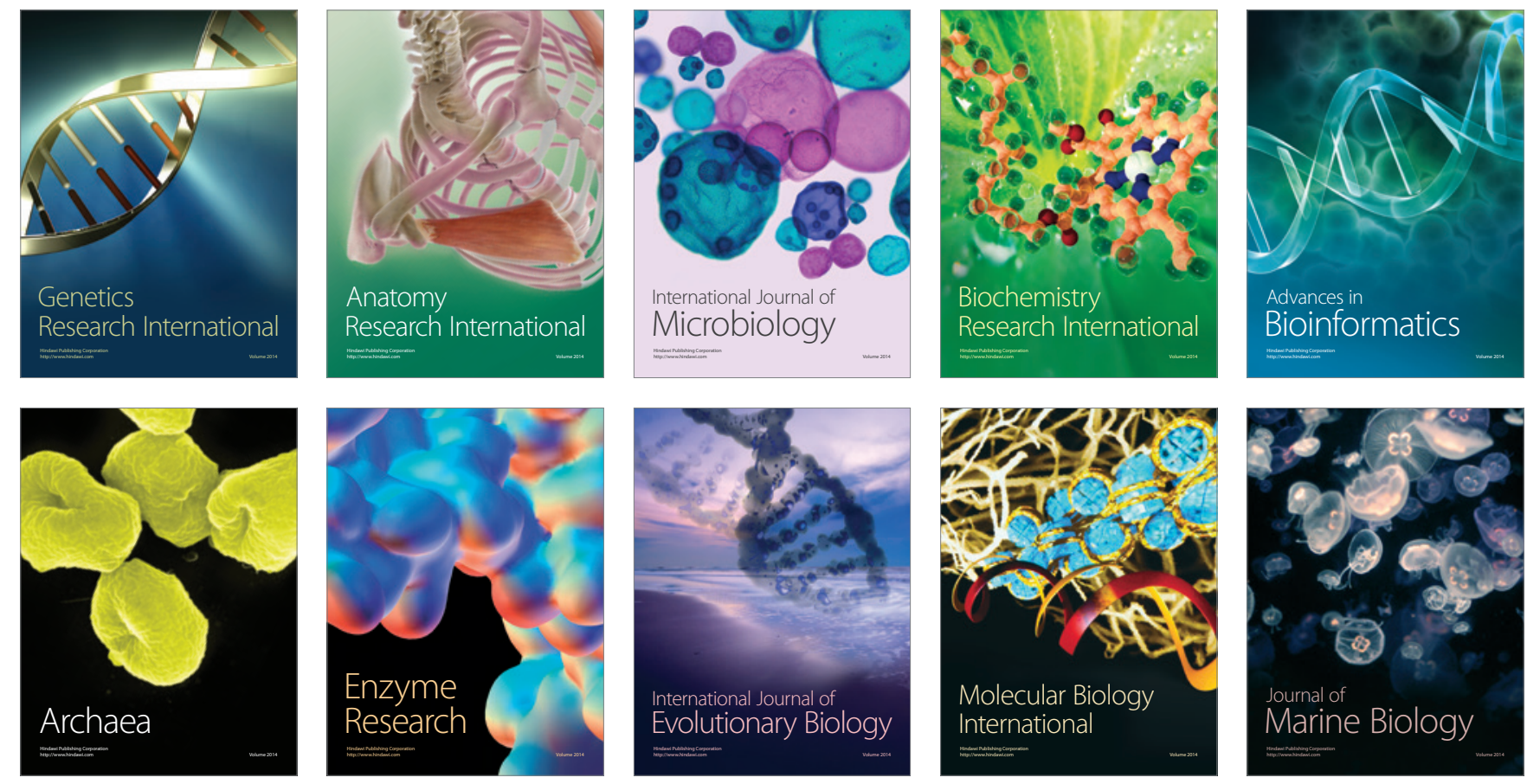